\title{
Multi-Walled Carbon Nanotubes Can Promote Brassica napus L. and Arabidopsis thaliana L. Root Hair Development through Nitric Oxide and Ethylene Pathways
}

\author{
Gan Zhao ${ }^{1}$, Yingying Zhao ${ }^{1}$, Wang Lou ${ }^{1}$, Dyaaaldin Abdalmegeed ${ }^{1}$, Rongzhan Guan ${ }^{2}$ and \\ Wenbiao Shen $1, *$ (D) \\ 1 Laboratory Center of Life Sciences, College of Life Sciences, Nanjing Agricultural University, Nanjing 210095, \\ China; 2018216033@njau.edu.cn (G.Z.); 2017116114@njau.edu.cn (Y.Z.); 2018116099@njau.edu.cn (W.L.); \\ 2018116158@njau.edu.cn (D.A.) \\ 2 State Key Laboratory of Crop Genetics and Germplasm Enhancement, Nanjing Agricultural University, \\ Nanjing 210095, China; guanrzh@njau.edu.cn \\ * Correspondence: wbshenh@njau.edu.cn; Tel./Fax: +86-258-439-6542
}

Received: 15 October 2020; Accepted: 29 November 2020; Published: 30 November 2020

\begin{abstract}
Here, we report that multi-walled carbon nanotubes (MWCNTs) can promote plant root hair growth in the species analyzed in this study; however, low and excessive concentrations of MWCNTs had no significant effect or even an inhibiting influence. Further results show that MWCNTs can enter rapeseed root cells. Meanwhile, nitrate reductase (NR)-dependent nitric oxide (NO) and ethylene syntheses, as well as root hair formation, were significantly stimulated by MWCNTs. Transcription of root hair growth-related genes were also modulated. The above responses were sensitive to the removal of endogenous $\mathrm{NO}$ or ethylene with a scavenger of $\mathrm{NO}$ or $\mathrm{NO} /$ ethylene synthesis inhibitors. Pharmacological and molecular evidence suggested that ethylene might act downstream of NR-dependent NO in MWCNTs-induced root hair morphogenesis. Genetic evidence in Arabidopsis further revealed that MWCNTs-triggered root hair growth was abolished in ethylene-insensitive mutants ein2-5 and ein3-1, and NR mutant nia1/2, but not in noa1 mutant. Further data placed NO synthesis linearly before ethylene production in root hair development triggered by MWCNTs. The above findings thus provide some insights into the molecular mechanism underlying MWCNTs control of root hair morphogenesis.
\end{abstract}

Keywords: multi-walled carbon nanotubes; root hair; nitric oxide; ethylene

\section{Introduction}

In 1991, Iijima first produced carbon nanotubes (CNTs), which were confirmed with high-resolution transmission electron microscopy [1]. Subsequent work produced abundant single-shell tubes with diameters of about one nanometer [2]. Their radial and axial dimensions are both on the order of micrometers, and both ends of the tubes are open. Due to their special structures and unique physical, chemical, biological properties, and huge application potential, they have received considerable attention [3-5]. Because of their excellent transmembrane and adsorption capacity [6], the research on CNTs' impact on agriculture is also emerging. Plants play vital roles in the ecological system; the edible parts of crops are possible routes for the uptake, translocation, and accumulation of CNTs, if they are used in agriculture [6,7]. In addition, CNTs can be toxic to animals and humans, mainly by inducing oxidative stress, mechanical damage, and affecting the activities of biological enzymes [8]. Therefore, 
to promote the application of CNTs in agriculture, the interactions between CNTs and plants need to be carefully elucidated.

Previous research on the relationship between CNTs and plants mainly focused on seed germination [9,10], primary root growth [11-13], lateral root development [14-16], flowering [17,18], and stress tolerance [19,20]. However, except for the studies of Joshi et al. [21] and García-Sánchez et al. [22], few investigations have been completed on the functions of multi-walled carbon nanotube (MWCNTs; one kind of CNTs) on root hairs and their corresponding mechanisms, and their phenotypes were controversial. Thus, the effects of CNTs on root hairs need to be further studied.

Root hair is one of the important components of root organogenesis. It could help the root system tightly integrating into the soil and increase the surface of the root system, thus helping plants successfully absorbing water and nutrients from the environment [23]. Also, root hair development can help plants grow out of trouble in a harmful environment [24].

During root hair development, ethylene is an important and essential signaling molecule [25-28]. ACC synthase and ACC oxidase, two critical enzymes responsible for ethylene biosynthesis, ubiquitously exist in plants [25-27]. Ethylene not only promotes the outgrowth of the root hair, but also induces the formation of root hairs on hairless cells $[25,26]$. These conclusions were based on the enhancement of root hair development observed in the presence of ethylene [26], 1-aminocyclopropane-1-carboxylic acid (ACC; an ethylene synthesis precursor), [27,28], and constitutive ethylene-responsive $c t r 1$ mutant [25]. Meanwhile, contrasting results were also confirmed in ein2 [26,27], ein3 [28], and etr [29], several ethylene-insensitive mutants, and in the wild type when exogenously applied with ethylene synthesis inhibitor cobalt chloride $\left(\mathrm{CoCl}_{2}\right)[29,30]$ and aminoethoxyvinylglycine (AVG) [25,29].

It is well documented that nitric oxide (NO) in plants can be produced through two routes, enzymatic or nonenzymatic ones. Between these, nitrate reductase (NR) and nitric oxide synthase (NOS)-like protein are two important enzymes responsible for synthesizing NO [27,31]. Like ethylene, NO was also confirmed to be an important signal molecule in plant root hair development [31-34]. This conclusion was based on the pharmacological and genetic evidence, showing that exogenously applied with a NO-releasing compound sodium nitroprusside (SNP) favors Arabidopsis root hair growth [31,34]. Whereas the defective phenomenon was observed in nia1/2 (impaired in nitrate reductase activity) $[27,34]$ and noa 1 (encoding NO-associated protein 1 ; exhibiting a reduced endogenous NO level indirectly), two NO-related mutants [31,34], and in the wild type when supplemented with the NO scavenger 2-(4-carboxyphenyl)-4,4,5,5 -tetramethylimidazoline-1-oxyl-3-oxide (c-PTIO) [31,32], NR inhibitor tungstate, and NOS inhibitor $N^{G}$-nitro- ${ }_{\mathrm{L}}$-arginine methyl ester hydrochloride (L-NAME) [27].

During plant development, it has been shown that both ethylene and NO can act both synergistically (in particular synergistically) and independently [34-36]. For example, several data place ethylene synthesis linearly after NO signaling in cell wall phosphorus reutilization in P-deficient rice [35], and ethylene and $\mathrm{NO}$ work together to induce root hair development in Arabidopsis upon the magnesium deficiency conditions [27]. By contrast, $\mathrm{NO}$ is also required for cucumber adventitious root development elicited by ethylene [36]. However, no detailed evaluation has yet been carried out to assess the contribution of ethylene and NO in MWCNTs-triggered other plant responses.

Here, by using a pharmacological approach, the effects of various concentrations of MWCNTs on plant root hair growth were evaluated in rapeseed (Brassica napus L.), the third most important source of vegetable oil worldwide [37]. Our findings showed that MWCNTs could dose-dependently affect root hair development in terms of changes in root hair density and length. The distribution of MWCNTs was also evaluated. Because both rapeseed and Arabidopsis are classified as cruciferous plants and a high homolog exists in their genomes [38], Arabidopsis ein2-5 and ein3-1, two ethylene-insensitive mutants, and nia1/2 and noa1, two NO mutants, were utilized to investigate the relationship between $\mathrm{NO}$ and ethylene. The evidence further revealed the important key roles of both ethylene and NO in 
MWCNTs-triggered root hair development, and ethylene may act downstream of NR-dependent NO signaling. The above results provided a unique mechanism for NO-ethylene interaction during root hair development triggered by MWCNTs, and presented a theoretical basis for the possible application of CNTs in agriculture.

\section{Results}

\subsection{MWCNTs-Stimulated Root Hair Growth and the Distribution of MWCNTs}

To provide the physiological effects of MWCNTs in root hair development, two-day-old rapeseed seedlings were treated with different concentrations of MWCNTs for 3 days. Compared with the control (Con), 10, 50, 100, 200, and $500 \mathrm{mg} / \mathrm{L}$ MWCNTs could differentially promote root hair development (Figure 1a,b). Among these treatments, the response of $100 \mathrm{mg} / \mathrm{L}$ MWCNTs was maximal, and this concentration was subsequently used. High concentrations (2000 and $5000 \mathrm{mg} / \mathrm{L}$ ) of MWCNTs were also applied in the study. The results showed that the root hair development could be seriously impaired by 2000 and $5000 \mathrm{mg} / \mathrm{L}$ MWCNTs, while no such significant decrease was found in the presence of $1000 \mathrm{mg} / \mathrm{L}$ MWCNTs (Supplementary Figure S1). Seven species, including rice (Oryza sativa L.), tomato (Solanum lycopersicum L.), Chinese cabbage (Brassica chinensis L.), wheat (Triticum aestivum L.), radish (Raphanus sativus L.), alfalfa (Medicago sativa L.), and Arabidopsis (Arabidopsis thaliana L.), were used subsequently. As shown in Supplementary Table S1, MWCNTs with appropriate concentrations can promote root hair growth, lower and higher concentrations of MWCNTs normally had no such significant effect on root hairs or even inhibited their growth.

(a) Con

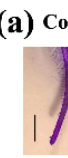

(b)

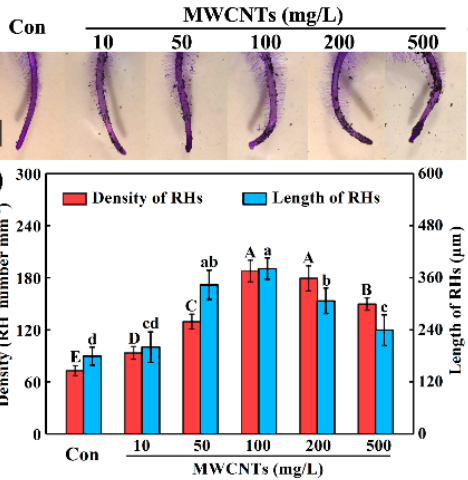

(c)

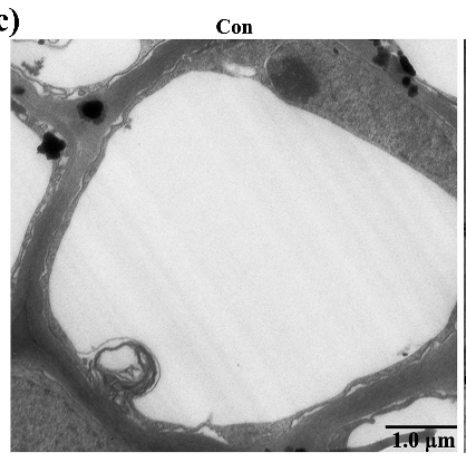

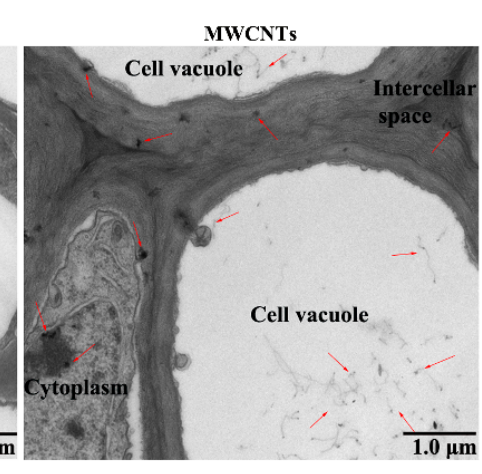

Figure 1. MWCNTs induced rapeseed root hair growth and the distribution of MWCNTs. Two-day-old seedlings were treated with the indicated concentrations of MWCNTs for 3 days. The sample without chemicals was the control (Con). Afterward, photographs of root hairs were taken after staining with $1 \%$ toluidine blue (a). Scale bar $=1 \mathrm{~mm}$. Meanwhile, the root hair (RH) density (b; left) and length (right) were measured. Within each set of experiments, bars with different letters are significantly different at $p<0.05$ according to Duncan's multiple range test. The distribution of MWCNTs was detected in rapeseed root tissues in response to $100 \mathrm{mg} / \mathrm{L}$ MWCNTs (c). The red arrows point to MWCNTs.

The distribution of MWCNTs was further detected by using transmission electron microscopy. The result showed that the MWCNTs were distributed in the cytoplasm, intercellular space, and cell vacuole of rapeseed root tissues, which are highlighted by the red arrows in Figure 1c.

\subsection{Ethylene Was Involved in MWCNTs-Induced Root Hair Development}

In order to assess whether ethylene participated in the MWCNTs-induced rapeseed root hair formation, we measured the contents of endogenous ethylene in root tissues by using gas chromatography. In comparison with the control sample, the time course analysis illustrated that the administration of MWCNTs for $18 \mathrm{~h}$ caused a progressive increase in the ethylene production, followed by peaking at $48 \mathrm{~h}$ and keeping a stable level until $72 \mathrm{~h}$ (Figure 2a). Meanwhile, two critical enzymes 
for ethylene synthesis, 1-aminocyclopropane-1-carboxylate (ACC) synthase, and ACC oxidase were also analyzed. Similar tendencies were observed in the above enzymatic activities (Figure 2b,c).
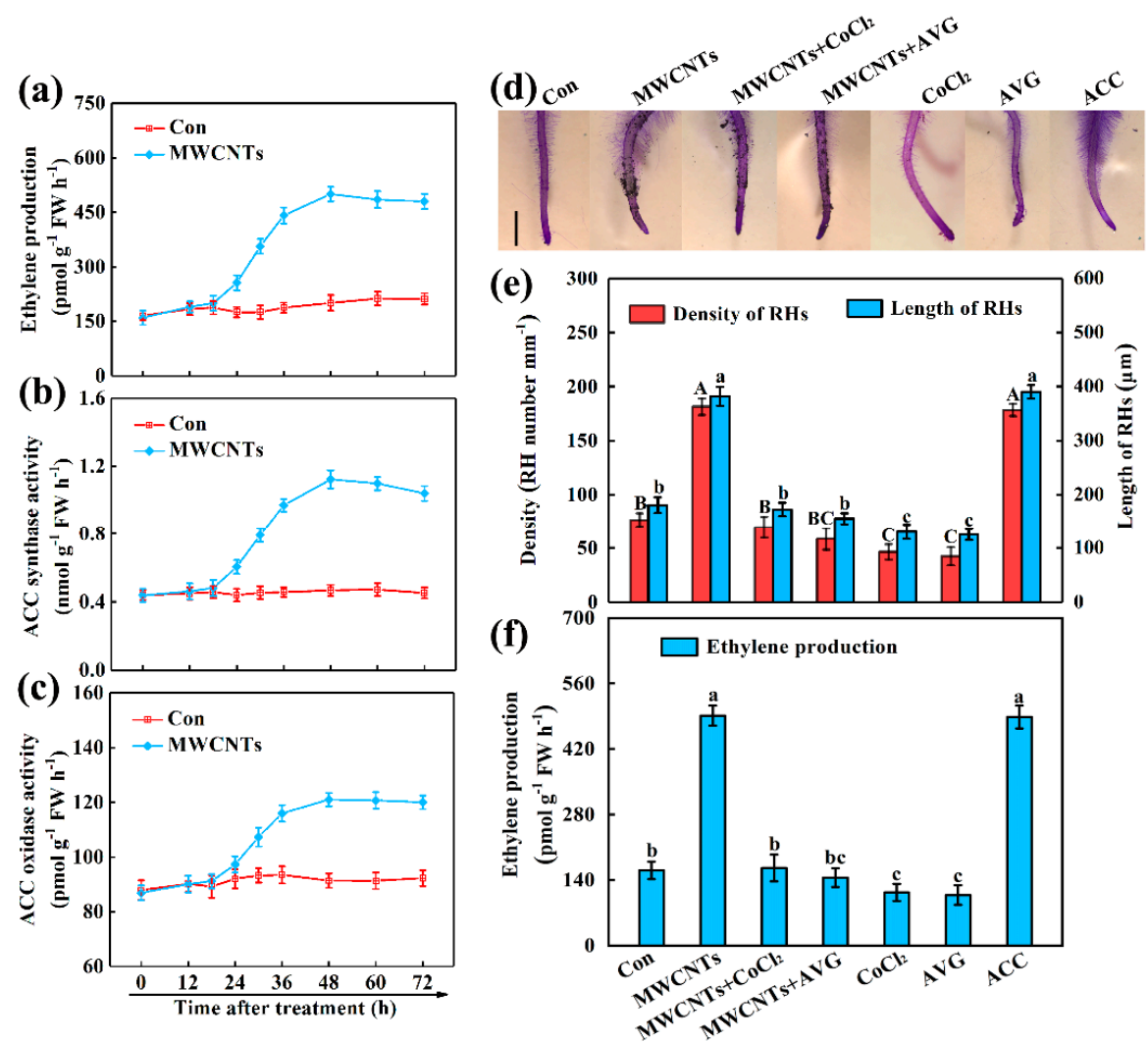

Figure 2. MWCNTs-induced ethylene production and root hair development were blocked by the removal of endogenous ethylene. Two-day-old rapeseed seedlings were treated with $100 \mathrm{mg} / \mathrm{L}$ MWCNTs, $10 \mu \mathrm{M} \mathrm{CoCl}_{2}$, and $3 \mu \mathrm{M}$ AVG, alone or in combinations. The sample without chemicals was the control (Con), and $3 \mu \mathrm{M}$ ACC alone was used as a positive control. Afterward, the time-course changes in ethylene production (a), ACC synthase (b), and ACC oxidase activities (c) were detected (in control and MWCNTs treated samples). After treatment for 3 days, corresponding photographs of the seedling's roots were done (d), and the root hair (RH) density and length (e), and ethylene production (f) were determined. Scale bar $=1 \mathrm{~mm}$. Within each set of experiments, bars with different letters were significantly different at $p<0.05$, according to Duncan's multiple range test.

Two ethylene synthesis inhibitors, cobalt chloride $\left(\mathrm{CoCl}_{2}\right)$ and aminoethoxyvinylglycine (AVG), were subsequently used. ACC, an ethylene synthesis precursor, was used as a positive control. The results showed that $10 \mu \mathrm{M} \mathrm{CoCl} 2$ or $3 \mu \mathrm{M}$ AVG could not only impaired root hair growth (Figure 2d,e) but also decreased ethylene content (Figure 2f). The MWCNTs-induced root hair development was similar to $3 \mu \mathrm{M} \mathrm{ACC}$, and it was inhibited by $\mathrm{CoCl}_{2}$ or AVG (Figure 2d,e). Meanwhile, the ethylene-induced by MWCNTs was significantly inhibited by $\mathrm{CoCl}_{2}$ or AVG (Figure 2f).

\subsection{NR-Dependent NO Was Associated with MWCNTs-Induced Root Hair Development}

$\mathrm{NO}$ is another gaseous signal molecule in root hair development. In order to evaluate a possible interaction between NO and MWCNTs in root hair development, the endogenous NO signal in rapeseed roots was firstly detected by 4-amino-5-methylamino- $2^{\prime}, 7^{\prime}$-difluorofluorescein diacetate (DAF-FM DA). As shown in Figure 3a, compared to the control samples, the fluorescence was significantly induced in the presence of MWCNTs, which showed the initial increase as early as $12 \mathrm{~h}$, and reached a peak at $48 \mathrm{~h}$ after treatment (Figure 3a, Supplementary Figure S2). In the time course, experiments found that in the presence of MWCNTs, the activities of NR showed similar tendencies, as compared to the levels 
of NO production (Figure 3b). However, no significant difference was observed in NOS-like enzyme activities of rapeseed seedlings with or without MWCNTs treatments (Figure 3c).
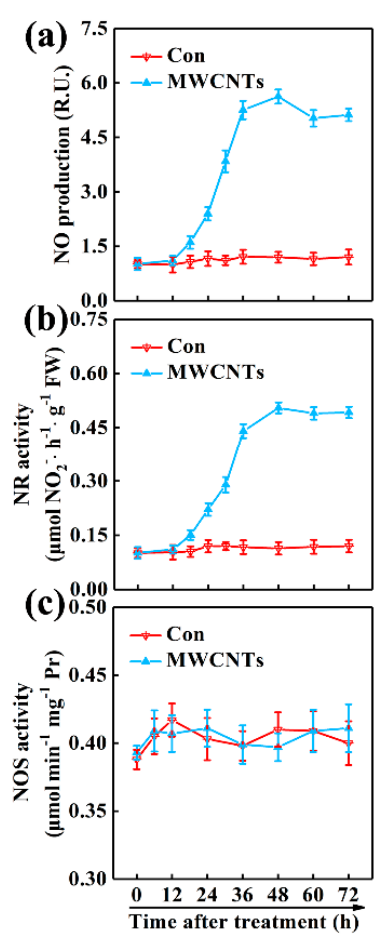

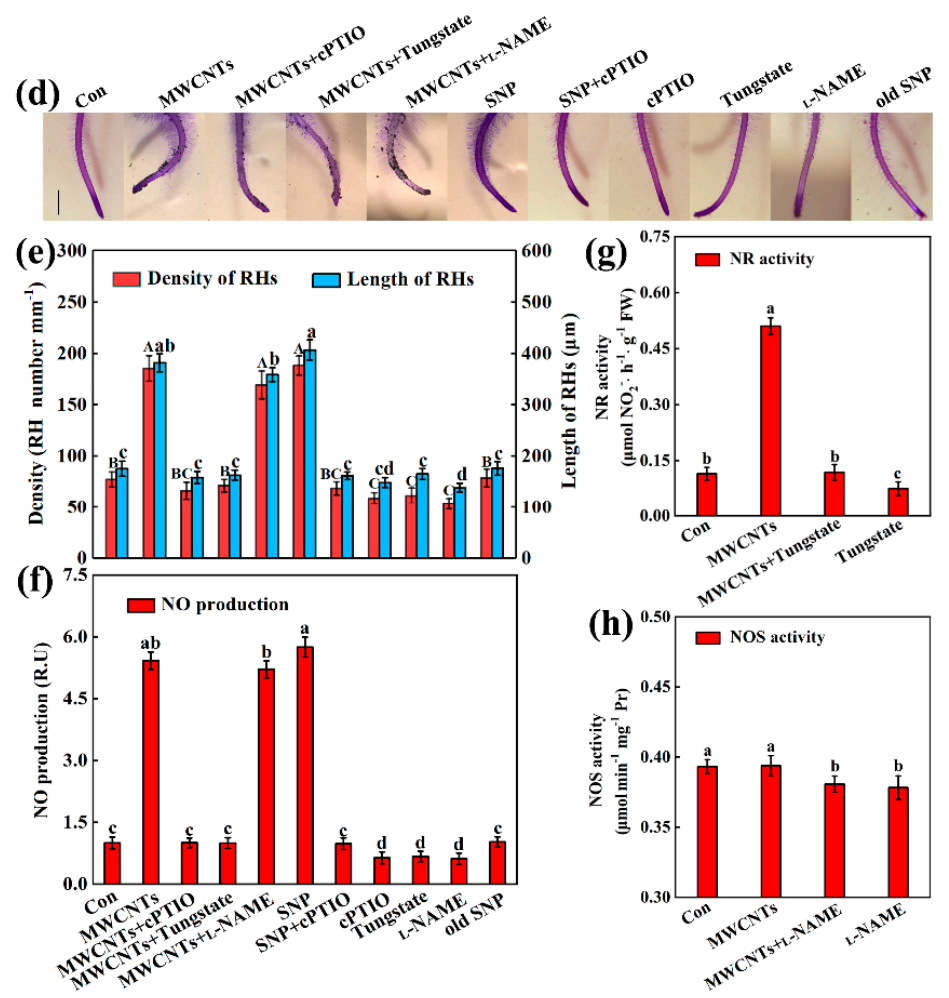

Figure 3. Nitric oxide production and root hair growth induced by MWCNTs were sensitive to CPTIO and tungstate. Two-day-old rapeseed seedlings were treated with $100 \mathrm{mg} / \mathrm{L}$ MWCNTs, $20 \mu \mathrm{M} \mathrm{SNP}$, $100 \mu \mathrm{M}$ cPTIO, $100 \mu \mathrm{M}$ tungstate, and $100 \mu \mathrm{M}_{\mathrm{L}}$-NAME, alone or their combinations. The sample without chemicals was the control (Con), and $20 \mu \mathrm{M}$ old SNP was used as the negative control of SNP. Afterward, the time-course changes in NO production (a), NR (b), and NOS activities (c) were detected (in control and MWCNTs treated samples). After treatments for 3 days, corresponding photographs (d), the root hair (RH) density and length (e), NO production (f), NR (g), and NOS activities (h) were provided or determined. Scale bar $=1 \mathrm{~mm}$. Within each set of experiments, bars with different letters are significantly different at $p<0.05$, according to Duncan's multiple range test.

NO-releasing compound SNP, NR inhibitor tungstate, mammalian NOS inhibitor $N^{\mathrm{G}}$-nitro-L-arginine methyl ester hydrochloride (L-NAME), and $\mathrm{NO}$ scavenger 2-(4-carboxyphenyl)4,4,5,5-tetramethylimidazoline-1-oxyl-3-oxiden potassium salt (cPTIO), were used in the subsequent experiments. Old SNP, containing no NO, but nitrate and ferrocyanide was used as a negative control of SNP. The results showed that when tungstate or ${ }_{L}$-NAME was applied alone, both root hair growth (Figure 3d,e) and NO production (Figure 3f) were simultaneously abolished. Meanwhile, old SNP failed to alter root hair development as well as NO production. Both MWCNTs- and SNP-promoted endogenous NO production and root hair development could be respectively blocked by cPTIO. cPTIO alone also resulted in decreased NO content and a significant reduction in root hair growth. In the presence of tungstate, MWCNT-induced NR activities, NO production, and root hair growth were significantly impaired (Figure 3d-g). MWCNTs had no obvious effects on NOS-like activities (Figure 3), and $\mathrm{L}_{\mathrm{N}} \mathrm{NAME}$ did not influence MWCNTs-induced NO (Figure 3f) and root hair development (Figure 3d,e). 


\subsection{Ethylene Acts Downstream of NO in MWCNTs-Induced Root Hair Growth}

The interaction between ethylene and $\mathrm{NO}$ was also examined in this study. The results showed that two ethylene synthesis inhibitors, $\mathrm{CoCl}_{2}$ and $\mathrm{AVG}$, did not alter $\mathrm{NO}$ synthesis, including its content, NR, and NOS activities, under the conditions in the presence and absence of MWCNTs (Figure $4 \mathrm{a}-\mathrm{d}$ ). Both $\mathrm{cPTIO}$ and tungstate could obviously block ethylene synthesis triggered by

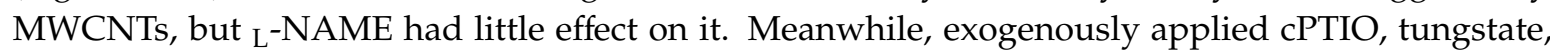
or $\mathrm{L}$-NAME alone could decrease ethylene content, and inhibit ACC synthase and oxidase activities (Figure $4 \mathrm{e}-\mathrm{g})$.
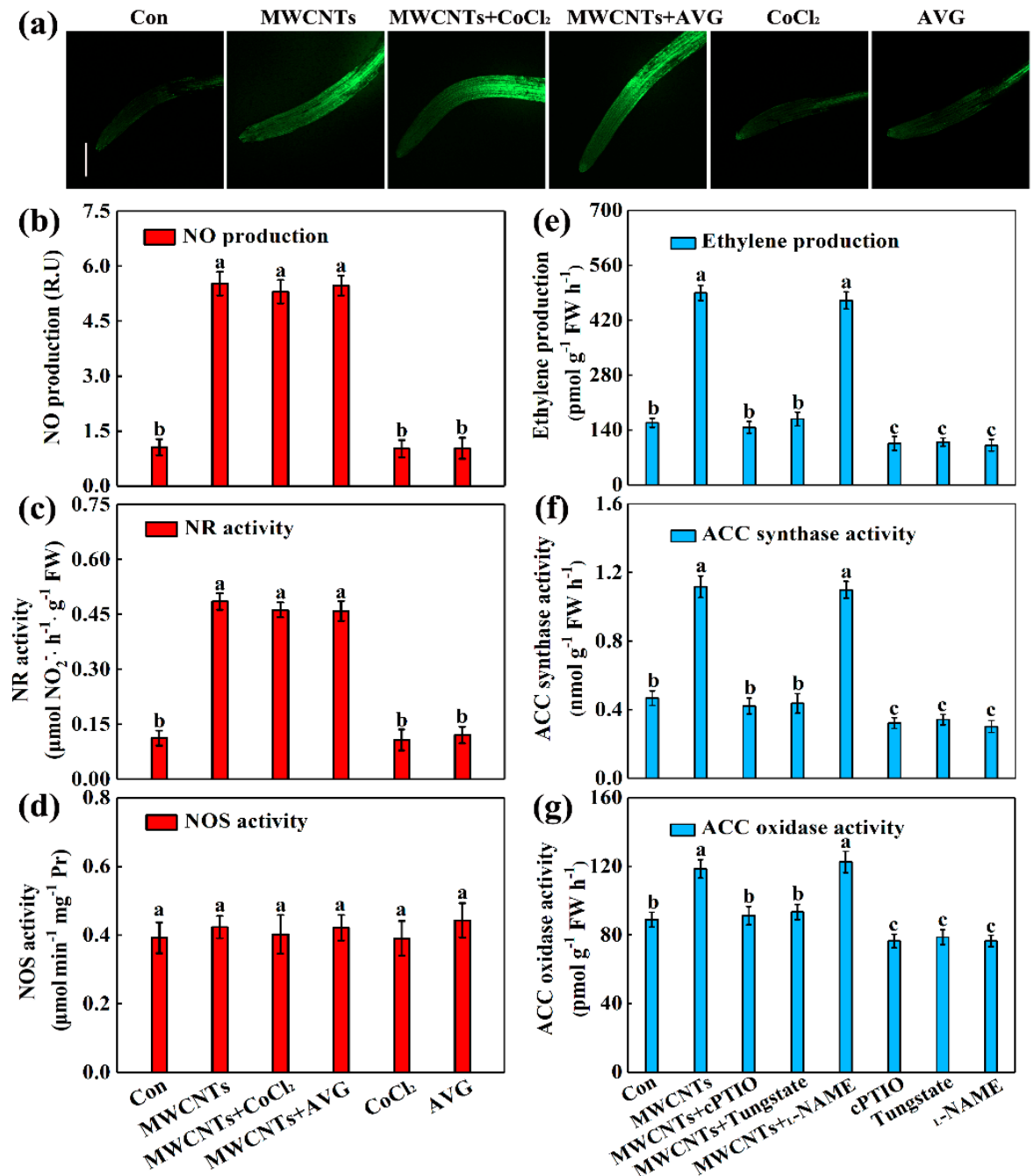

Figure 4. Cross-talk between $\mathrm{NO}$ and ethylene. Two-day-old rapeseed seedlings were treated with $100 \mathrm{mg} / \mathrm{L}$ MWCNTs, $10 \mu \mathrm{M} \mathrm{CoCl}_{2}, 3 \mu \mathrm{M}$ AVG, $100 \mu \mathrm{M}$ cPTIO, $100 \mu \mathrm{M}$ tungstate, and $100 \mu \mathrm{M}_{\mathrm{L}}$-NAME, alone or in combinations for $48 \mathrm{~h}$. Afterward, endogenous NO levels (a) were determined by laser scanning confocal microscopy, and the corresponding fluorescence densities (b), NR (c), and NOS activities (d) were detected. Scale bar $=0.2 \mathrm{~mm}$. Meanwhile, ethylene production (e), ACC synthase (f), and ACC oxidase activities (g) were also detected. The sample without chemicals was the control (Con). Bars with different letters are significantly different at $p<0.05$, according to Duncan's multiple range test. 
2.5. MWCNTs-Modulated Transcripts Related to Root Hair Development were Dependent on NO and Ethylene Synthesis

The transcripts of auxin signal-related genes AUXINRESISTANT1 (AUX1) and PIN-FORMED1 (PIN1) and root hair development-related genes TRANSPARENT TESTA GLABRA (TTG), GLABRA2 (GL2), CAPRICE (CPC), and TRIPTYCHON (TRY) were quantified by qPCR. Like the responses of ACC and SNP, the expression of BnAUX1, BnPIN1, BnCPC, and BnTRY were up-regulated in MWCNTs-induced rapeseed root hair growth, and the expression of BnTTG and BnGL2 were down-regulated (Figure 5). The above responses could be differentially blocked or impaired by the addition of $\mathrm{CoCl}_{2}$, AVG, cPTIO, and tungstate (Figure 5).

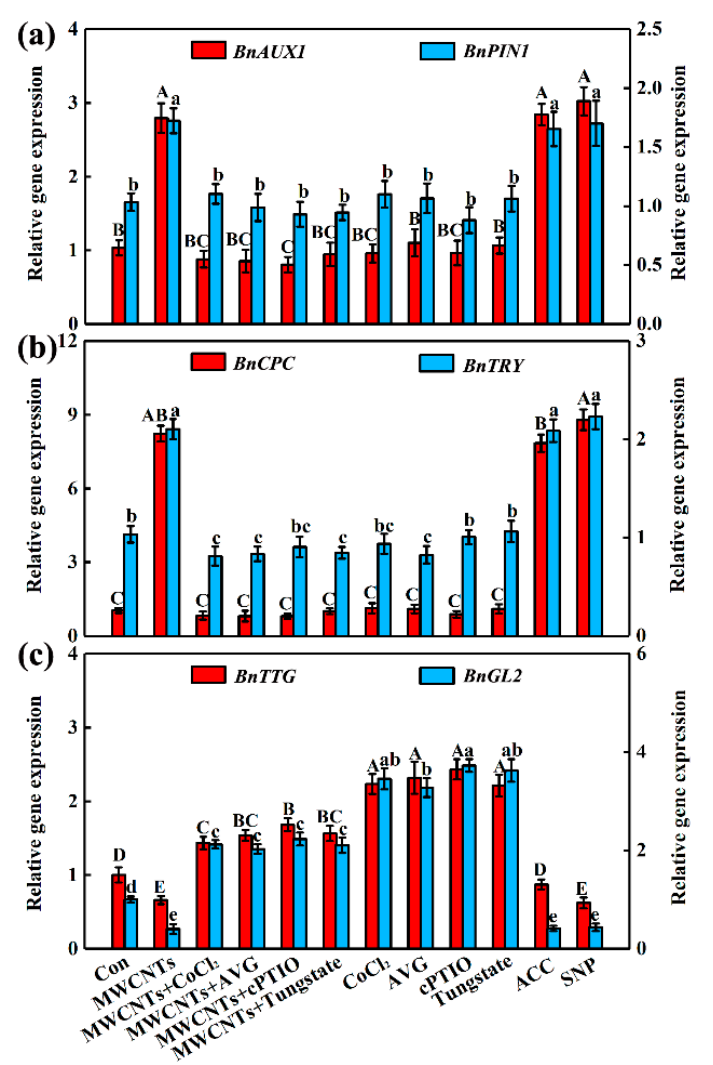

Figure 5. The transcripts levels of root hair development-related genes. Two-day-old rapeseed seedlings were treated with $100 \mathrm{mg} / \mathrm{L}$ MWCNTs, $10 \mu \mathrm{M} \mathrm{CoCl}_{2}$, and $3 \mu \mathrm{M}$ AVG, $100 \mu \mathrm{M}$ cPTIO, $100 \mu \mathrm{M}$ tungstate, $3 \mu \mathrm{M}$ ACC, and $20 \mu \mathrm{M}$ SNP, alone or in combinations for $24 \mathrm{~h}$. Afterward, BnAUX1 and BnPIN1 (a), BnCPC and BnTRY (b), and BnTTG and BnGL2 (c) transcriptional levels were analyzed by qPCR. The sample without chemicals was the control (Con). Within each set of experiments, bars with different letters are significantly different at $p<0.05$, according to Duncan's multiple range test.

2.6. Genetic Evidence Revealed that Ethylene and NR-Dependent NO Were Associated with MWCNTs-Induced Root Hair Development

To complement the above results, the genetic mutants of Arabidopsis were subsequently used. The mutants used in the experiment were NO related mutant nia1/2 (exhibited impaired nitrate reductase activity) and noa1 (encoding NO-associated protein 1; with indirectly reduced NO level in vivo), and ethylene related mutant ein2-5 (ethylene-insensitive mutant) and ein3-1 (ethylene-insensitive mutant).

Lower root hair density in these four mutants and shorter root hairs in ein2-5 and ein3-1 were detected in this study (Figure 6a-c). For nia1/2 and noa1 mutants, under the control condition, the obvious reduction in NO and ethylene contents were observed (Figure $6 \mathrm{~d}, \mathrm{f}$ ), matched with the 
phenotypes of the root hairs, compared to the wild type (WT) plants (Figure 6a-c). The biochemical analysis further showed that no NR activity was detected in nia1/2 mutant, normal NR activity was detected in noa1 mutant (Figure 6e), but a similar and significant reduction in NO content was observed in two mutants (Figure 6d). Meanwhile, no such significant decreases in the NO and ethylene signals were observed in ein2-5 and ein3-1 mutants, and the decreased ethylene contents were also observed in nia1/2 and noa1 mutants (Figure 6e,g).

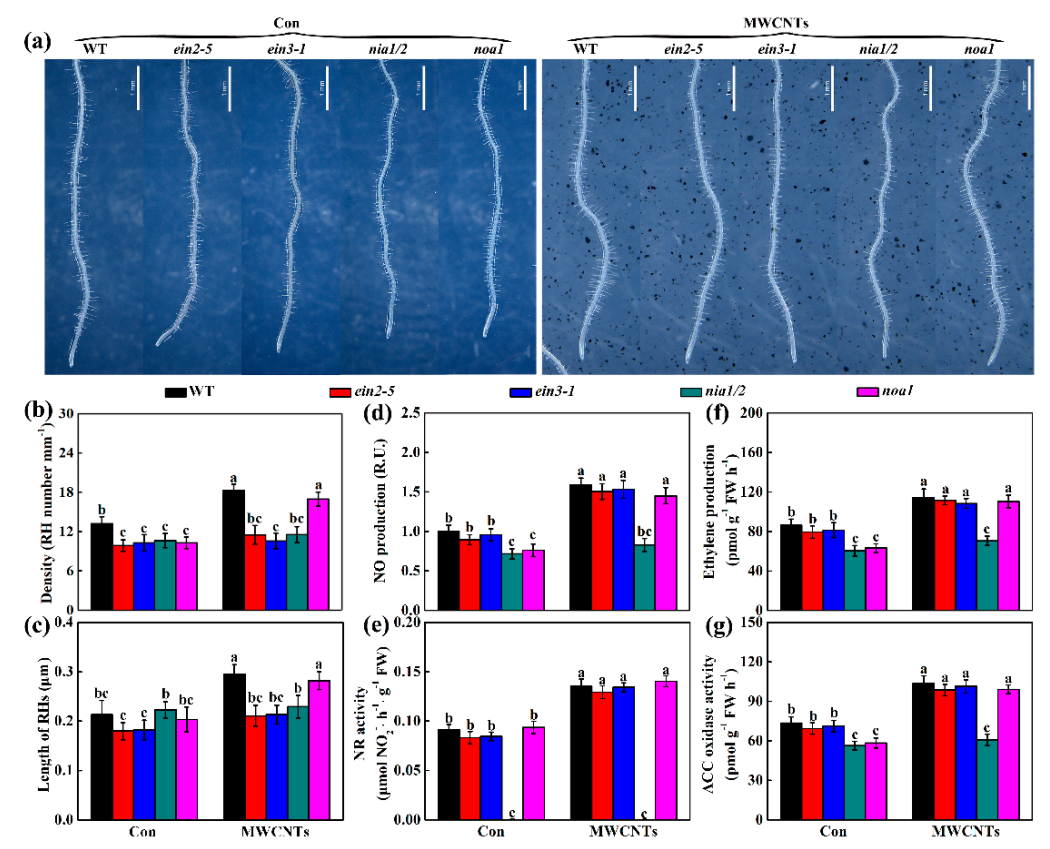

Figure 6. The involvement of NO and ethylene in MWCNTs-triggered root hair development in Arabidopsis. Five-day-old WT, ein2-5, ein3-1, nia1/2, and noa1 mutant plants were grown on MS medium for $5 \mathrm{~d}$ and then transplanted to a medium with or without $10 \mathrm{mg} / \mathrm{L}$ MWCNTs. After treatments for $5 \mathrm{~d}$, corresponding photographs (a), the root hair $(\mathrm{RH})$ density $(\mathbf{b})$, and length (c) were provided and determined. NO content (d), NR activity (e), ethylene content (f), and ACC oxidase activity (g) were also detected after treatments for 3 days. Bars with different letters are significantly different at $p<0.05$, according to Duncan's multiple range test.

Subsequent experiments discovered that the application of MWCNTs could induce root hair growth in WT and noa1 mutants. Consistently, a significant reduction in root hair development was found in nia1/2 mutant when challenged with MWCNTs (Figure 6a-c). A similar phenomenon was observed in ein 2-5 and ein3-1 mutants. Related ethylene and NO synthesis were also examined in the above materials. As anticipated, changes in ethylene and NO contents matched with phenotypes, showing higher ethylene and NO contents in MWCNTs-treated WT, noa1, ein2-5, and ein3-1 mutants, which differ from the impaired ethylene and NO contents in nia1/2 mutant (Figure 6d,f).

The cross-talk between ethylene and NO was further investigated. As shown in Supplementary Figure S3, by using tungstate, an inhibitor of NR, and AVG, an inhibitor of ACC synthetase, we observed that the removal of the major known sources of NO or ethylene severely impaired MWCNTs-induced ethylene production and thereafter root hair formation.

Here, we further evaluated the roles of auxin signaling in MWCNTs response, and found that YFP and GFP fluorescence in the roots of AUX1::AUX1-YFP and PIN1::PIN1-GFP transgenic plants were increased by MWCNTs, both of which could be differentially impaired in the presence of either tungstate or AVG (Figure 7a,b). The changes of AtAUX1 and AtPIN1 transcripts levels were also confirmed by using qPCR in WT, nia1/2, and ein2-5 under normal or MWCNTs-treated condition, showing the decreasing tendencies in two mutants, especially upon MWCNTs (Figure 7c,d). Furthermore, 
root hair growth-related genes, including AtCPC, AtTRY, AtROP2, AtTTG1, AtGL2, and AtGL3, were also analyzed. Compared to the WT in either the control condition or in the presence of MWCNTs, the down-regulated AtCPC (except in the control conditions), AtTRY and AtROP2, and the up-regulated AtTTG1, AtGL2, and AtGL3 in both nia1/2 and ein2-5 mutants were observed (Figure 8).
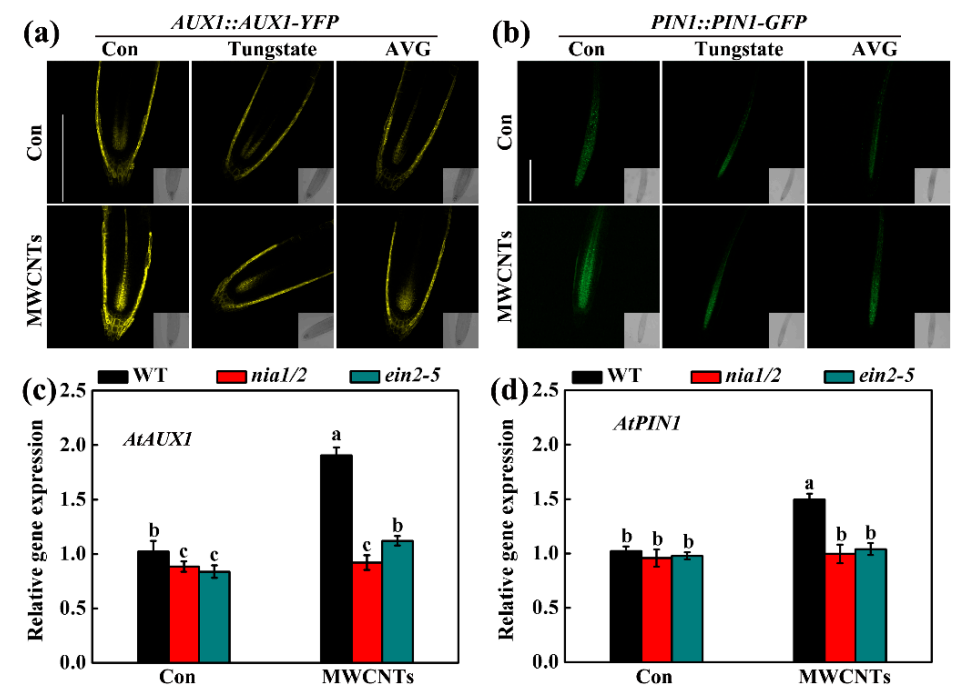

Figure 7. Changes in AUX1 and PIN. Five-day-old Arabidopsis seedlings were treated with $10 \mathrm{mg} / \mathrm{L}$ MWCNTs, $50 \mu \mathrm{M}$ tungstate, and $2 \mu \mathrm{M}$ AVG, alone or their combinations for $24 \mathrm{~h}$. Afterward, the YFP fluorescence images of $A U X 1:: A U X 1-Y F P(\mathbf{a})$ and the GFP fluorescence images PIN1::PIN1-GFP (b) roots were detected by laser scanning confocal microscopy. Scale bar $=0.2 \mathrm{~mm}$. The mRNA expression of AtAUX1 (c) and AtPIN1 (d) in root tissues were analyzed by qPCR. Bars with different letters are significantly different at $p<0.05$, according to Duncan's multiple range test.

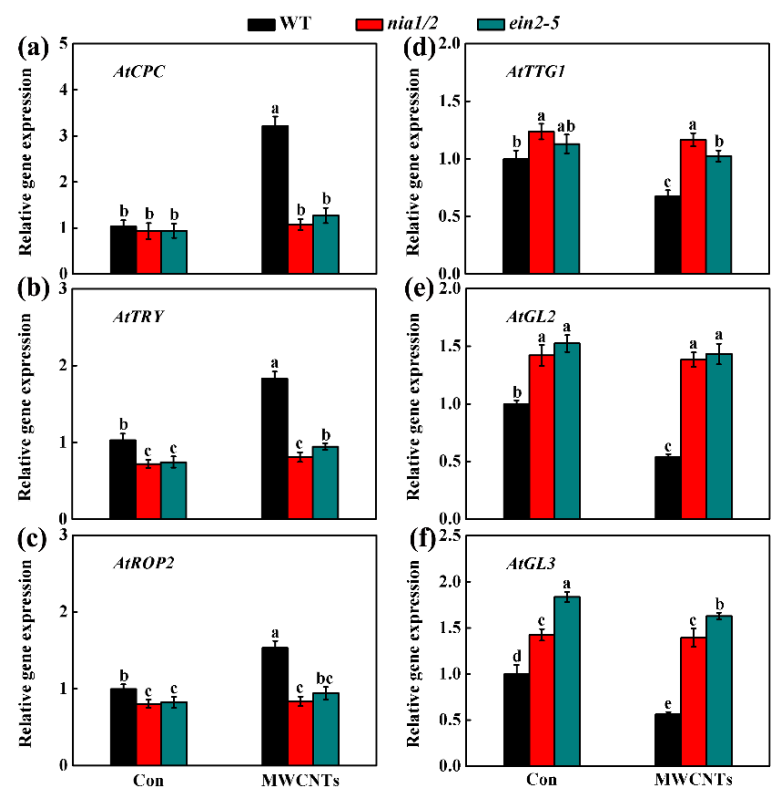

Figure 8. Changes in the transcripts of genes related to root hair formation in Arabidopsis. Five-day-old WT, nia1/2, and ein2-5 mutants were grown on MS medium for $5 \mathrm{~d}$, and then transplanted to medium with or without $10 \mathrm{mg} / \mathrm{L}$ MWCNTs for $24 \mathrm{~h}$. Seedlings grown on MS medium without MWCNTs were the control (Con). Afterwards, the mRNA expression of $\operatorname{AtCPC~(a),~AtTRY~(b),~AtROP2~(c),~}$ AtTTG1 (d), AtGL2 (e), and AtGL3 (f) in root tissues were analyzed by qPCR. Bars with different letters are significantly different at $p<0.05$, according to Duncan's multiple range test. 


\section{Discussion}

MWCNTs could affect plant growth and stress resistance. However, few studies have focused on root hairs, and their conclusions are controversial. A previous study showed that MWCNTs (diameters ranging from 13 to $14 \mathrm{~nm}$ ) could significantly promote root hair growth in 70, 80, and $90 \mathrm{mg} / \mathrm{L}$ in wheat [21]. However, a controversial result was reported by García-Sánchez et al. [22], which revealed that $25 \mathrm{mg} / \mathrm{L} \mathrm{COOH}-\mathrm{MWCNTs}$ (diameters ranging from 4 to $12 \mathrm{~nm}$; and the modification increases the solubility of MWCNTs) could obviously inhibit root hair growth in Arabidopsis. To provide a more detailed analysis of the physiological effects of MWCNTs in root hair development, different concentrations of MWCNTs were used to treat rapeseed (Figure 1a,b and Supplementary Figure S1) and seven other species, including rice, tomato, Chinese cabbage, wheat, radish, alfalfa, and Arabidopsis (Supplementary Table S1). The results revealed that MWCNTs could differentially influence the growth of root hairs depending on concentration. MWCNTs with appropriate concentrations can promote plant root hair growth in the species analyzed. Further results showed that the MWCNTs were distributed in the cytoplasm, intercellular space, and cell vacuole of rapeseed root tissues (Figure 1c), consistent with the previous study [13]. These results could provide a basis for the toxicity study of MWCNTs.

In most plants, ethylene signaling is indispensable in root hair development [25-29]. In this study, the time course analysis illustrated that ethylene production could be induced by MWCNTs in rapeseed seedling roots (Figure 2a). Meanwhile, similar tendencies were observed in ACC synthase and ACC oxidase (Figure $2 b, c)$. Ethylene synthesis, in response to MWCNTs in rapeseed, also corresponded with the biological response of MWCNTs control of root hair development (Figure 1a,b). These results inferred that ethylene may be involved in MWCNTs-induced root hair growth. Subsequently, ethylene synthesis inhibitors $\mathrm{CoCl}_{2}[29,30]$ and AVG [30,35] were applied to individually decrease ACC oxidase and its synthetase activities, not only impaired root hair growth (Figure 2d,e), but also decreased ethylene content (Figure 2f). The above results clearly confirmed the important function of endogenous ethylene in root hair development, consistent with previous studies [25-28]. Further results in this study revealed that MWCNTs control of root hair development was similar to the induction role of $3 \mu \mathrm{M}$ ACC. By contrast, MWCNTs-induced root hair growth was inhibited by $\mathrm{CoCl}_{2}$ or AVG (Figure 2d,e). Meanwhile, $\mathrm{CoCl}_{2}$ or AVG inhibition of MWCNTs-triggered ethylene was also observed (Figure 2f), indicating a requirement for ethylene in MWCNTs control of root hair development. Similar results were discovered in the previous studies, showing that the removal of endogenous ethylene could impair root hair growth $[25,26]$, since ethylene is an essential signal for controlling root hair development in either nutrient-adequate conditions $[26,28]$ or nutrient-starvation surroundings $[27,34]$.

Similar to ethylene [25-28], NO is another important signal molecule in root hair development [31,32]. Figure 3a proved that NO was significantly induced by MWCNTs, showing the initial increase as early as $12 \mathrm{~h}$, and reaching a peak at $48 \mathrm{~h}$ after treatment (Figure 3a, Supplementary Figure S2). The results clearly suggest that MWCNTs-induced NO is an early event. NR and NOS-like protein are two important enzymes responsible for synthesizing NO in plants [39,40]. From the detection of NR and NOS-like pathways in MWCNTs-treated samples (Figure 3b,c), we inferred that NR was the main enzymatic route for MWCNTs-induced NO. This is consistent with previous studies no matter in plant response against stress [13] or lateral root formation [41]. NR inhibitor tungstate [42,43],

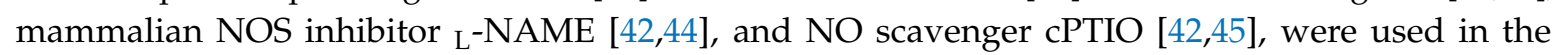
subsequent experiments. The results showed that both root hair growth (Figure $3 \mathrm{~d}, \mathrm{e}$ ) and NO production (Figure $3 \mathrm{f}$ ) were simultaneously abolished by tungstate, L-NAME, or CPTIO, emphasizing the important function of endogenous NO in root hair morphogenesis like previous studies [31,32]. In the presence of tungstate, MWCNT-induced NR activities were also significantly impaired (Figure 3g), thus leading to a decreased NO production (Figure 3f) and a reversed phenotype (Figure 3d,e). Comparatively, MWCNTs had no obvious effects on NOS-like activities (Figure 3), and L-NAME did not influence MWCNTs-induced NO (Figure 3f) and root hair development (Figure 3d,e). Those results thus suggested that NOS might not be the main source for NO production elicited by MWCNTs. Similar phenomena were reported in other plant species, including Arabidopsis [46], red kidney bean [47], 
and barley [48]. Combining the above mentioned results, we further proved that MWCNTs-induced root hair development is dependent on NR-mediated NO synthesis.

Ample evidence revealed that $\mathrm{NO}$ and ethylene are key signaling molecules participating in various plant signal transduction processes. For example, both ethylene [25,26] and NO [31-34] are individually suggested to induce root hair growth. However, the question of the relationship between ethylene and NO in MWCNTs-elicited root hair growth appears to be particularly interesting. As shown in Figures 2a and 3a, MWCNTs application stimulated the synthesis of NO and ethylene, and the initial inducible time points were $12 \mathrm{~h}$ and $18 \mathrm{~h}$, indicating that $\mathrm{NO}$ might act upstream of ethylene in MWCNTs-triggered root hair development. Subsequent experiments further proved that NO is upstream of ethylene by detecting the effects of two ethylene synthesis inhibitors $\mathrm{CoCl}_{2}$ and AVG on the NO content induced by MWCNTs; and the effects of the NO scavenger CPTIO, its synthesis inhibitors tungstate and $\mathrm{L}_{\mathrm{NAME}}$, on the ethylene content induced by MWCNTs (Figure 4). So, by combining data from Figures 2-4, we concluded that some linearity may exist in NO and ethylene signaling downstream of MWCNTs. Interestingly, a similar relationship of $\mathrm{NO}$ and thereafter ethylene signaling was observed in the adaptive response of phosphorus-deficient rice [35]. The interaction relationship between NO and ethylene was found in a magnesium-deficiency condition [27]. Therefore, it could be suggested that plant response to an external stimulus is controlled by a complex array of signaling mechanisms, and plants respond differently to various environmental stimuli with the same signals, in a linear fashion or a cross-talk manner.

It is well documented that the transcripts of TRANSPARENT TESTA GLABRA (TTG), GLABRA2 (GL2), and GLABRA3 (GL3) could promote the development of epidermal cells to nonhair cells, thus resulting in the inhibition in the initiation of root hair development $[49,50]$. The Rho-related GTPase from plants $(R O P)$ is closely associated with root hair initiation and tip growth [51,52]. Correspondingly, the transcripts of CAPRICE (CPC) and TRIPTYCHON (TRY) are known to trigger root hair formation [49,50]. Auxin signal-related genes AUXINRESISTANT1 (AUX1) and PIN-FORMED1 (PIN1) participate in ethylene- and NO-elicited root hair formation via regulating corresponding marker genes related to root hair development $[34,53,54]$. Accordingly, the transcripts levels of the above molecular marker genes related to root hair growth were detected (Figure 5). The results indicate that both ethylene and NO are required to modulate these molecular marker genes in MWCNTs control of root hair development. Similarly, previous results also revealed that the genes related to root hair growth were regulated in magnesium deficiency-promoted root hair growth via ethylene and NO signals [34]. The above results indicated that MWCNTs-induced root hair growth is closely associated with the adjustment of the marker gene expression.

Pharmacological experiments may not fully reflect the true roles of endogenous ethylene and NO signals in root hair development and may have side effects [55]. So, the genetic mutants of Arabidopsis, which have high homology to rapeseed [38], were also used in the study. Previous reports discovered that nia1/2, noa1, ein2-5, and ein3-1 showed poor root hair growth $[27,34]$. Similar results were obtained in our study, showing lower root hair density in these four mutants, and shorter root hairs in ein2-5 and ein3-1 (Figure 6a-c), indicating that endogenous ethylene and NO function in plant root hair growth. While, no such significant decreases of $\mathrm{NO}$ and ethylene signals were detected in ein 2-5 and ein3-1 (Figure 6d-g). These could be explained by the fact that both ein 2-5 and ein3-1 are ethylene-receptor-related mutants that have little effect on endogenous ethylene [56-60]. Further results showed that the application of MWCNTs could induce root hair growth in WT and noa1, not in nia1/2. (Figure $6 \mathrm{a}-\mathrm{c}$ ), reflecting the important function of NR and ethylene in the above response. The cross talk between ethylene and NO was investigated by using tungstate, an inhibitor of NR, and AVG, an inhibitor of ACC synthetase. As shown in Supplementary Figure S3, the removal of the major known sources of $\mathrm{NO}$ or ethylene severely impaired MWCNTs-induced ethylene production and, thereafter, root hair formation. These further indicated a requirement for ethylene in the above MWCNTs responses. Moreover, since AVG did not affect NO production, we further confirm that ethylene acts downstream of NO signaling in MWCNTs governing root hair morphogenesis. 
Auxin, a well-known phytohormone, has an important function in controlling root hair growth [31,34]. Previous genetic evidence discovered that auxin might function downstream of ethylene and NO signaling to promote Arabidopsis root hair formation under magnesium deficiency conditions [34]. It is well documented that auxin transport is mediated by AUXINRESISTANT1 (AUX1)/LAX influx carriers and the PIN-FORMED (PIN) efflux carrier family [51,52]. For example, it was documented that AUX1 could increase the efficiency of auxin uptake, thus resulting in the efficient transport of auxin and its accumulation within plant tissues. Here, by detecting YFP and GFP fluorescence in MWCNTs-treated AUX1::AUX1-YFP and PIN1::PIN1-GFP transgenic plants roots in the presence of either tungstate or AVG (Figure 7a,b), and the transcript levels of AtAUX1 and AtPIN1 in WT, nia1/2, and ein2-5 under normal or MWCNTs-treated condition (Figure 7c,d), we inferred that auxin might be controlled by ethylene and NO in MWCNTs control of Arabidopsis root hair development. Furthermore, the transcript levels of root hair growth-related representative genes, including AtCPC, AtTRY, AtROP2, AtTTG1, AtGL2, and AtGL3 [50-52], in WT, nia1/2, and ein2-5 under normal or MWCNTs-treated condition (Figure 8) also pointed out that the molecular maker genes associated with root hair growth could be modulated by MWCNTs via NO-ethylene pathway.

Combining the above results in rapeseed and Arabidopsis, we proposed that both ethylene and NO were required for MWCNTs-induced root hair morphogenesis, and ethylene might act downstream of $\mathrm{NO}$ in the regulatory cascade. The involvement of auxin signaling was also suggested. A related model is summarized in Figure 9.

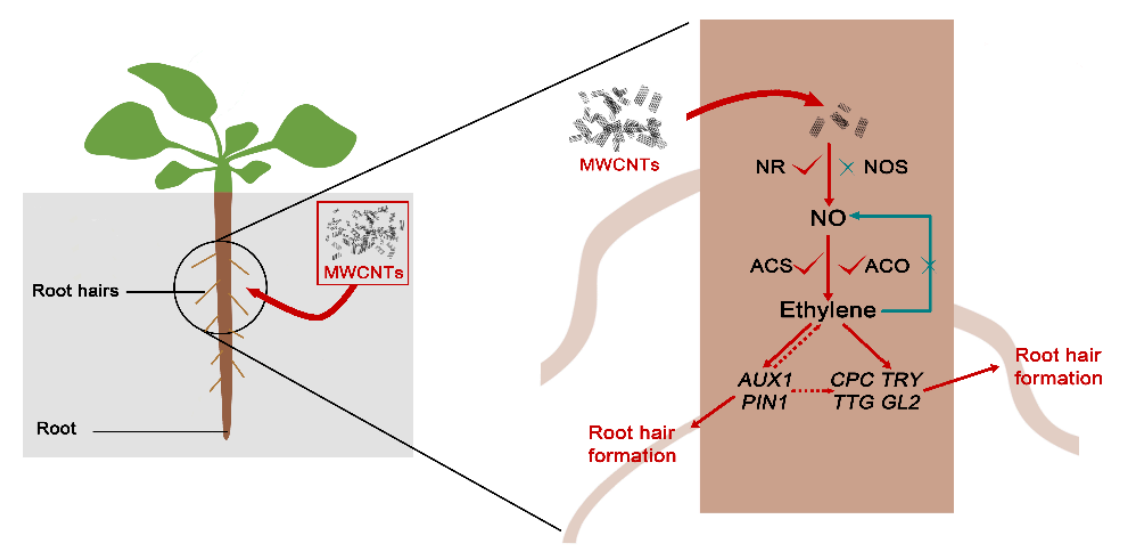

Figure 9. A model depicting the involvement of NO and ethylene in MWCNTs-induced root hair development.

\section{Materials and Methods}

\subsection{Chemicals}

All chemicals were obtained from Sigma-Aldrich (St Louis, MO, USA) unless stated otherwise. The chemicals included: multi-walled carbon nanotubes (MWCNTs), 1-aminocyclopropane-1carboxylic acid (ACC; an ethylene synthesis precursor) [28,30], cobalt chloride $\left(\mathrm{CoCl}_{2}\right.$; an inhibitor of ACC oxidase) [29,30], aminoethoxyvinylglycine (AVG; an inhibitor of ACC synthetase) [29,35], sodium nitroprusside (SNP; a NO-releasing compound) [31,34], 2-(4-carboxyphenyl)-4,4,5,5tetramethylimidazoline-1-oxyl-3-oxide (c-PTIO; a specific scavenger of NO) [35,36], tungstate (an inhibitor of nitrate reductase) [42,44], $N^{\mathrm{G}}$-nitro-L-arginine methyl ester hydrochloride (L-NAME; a mammalian NO synthase inhibitor) [42,43]. Additionally, the old SNP solution, produced by keeping SNP solution for at least $10 \mathrm{~d}$ in the light to eliminate the whole NO, was regarded as a negative control of SNP $[42,43]$. The concentrations of the above chemicals were confirmed in exploratory experiments, from which the maximal effects were confirmed. 
The characterization of MWCNTs was carried out in our recent study [13]. They were prepared according to the methods described previously [11,13]. The obtained homogenate colloidal suspension was immediately used.

\subsection{Plant Materials and Growth Conditions}

Rapeseed (Brassica napus L. Zhongshuang 11) was purchased in the Chinese Academy of Agricultural Sciences. Seeds were surface-sterilized and cultured according to previous research methods [13]. Briefly, seeds were germinated for 2 days at $25^{\circ} \mathrm{C}$ in the darkness, then the identical seedlings were cultured in the 1/2 Murashige and Skoog (MS, pH 5.8) medium at a light intensity of $200 \mu \mathrm{mol} \mathrm{m}{ }^{-2} \mathrm{~s}^{-1}$ and $16-\mathrm{h} / 8-\mathrm{h}\left(25 \pm 1 / 23 \pm 1{ }^{\circ} \mathrm{C}\right)$ day/night regimes, with the indicated chemicals detailed described in the Figure legends.

Arabidopsis thaliana cv. Columbia (Col-0) was used in this study. The wild type (WT), noa1, and nia1/2 mutants were obtained from the Arabidopsis Biological Resource Center (http://www. Arabidopsis.org/abrc), and the ein2-5, ein3-1, AUX1::AUX1-YFP, and PIN1::PIN1-GFP mutants were generous gifts from C.W. Jin, Zhejiang University, Hangzhou, China.

Arabidopsis seeds were surface-sterilized and cultured on the solid 1/2 MS medium containing $1 \%(w / v)$ agar and $1 \%(w / v)$ sucrose at $4{ }^{\circ} \mathrm{C}$ for 2 days in darkness. Afterward, seeds were grown in a growth chamber at a light intensity of $100 \mu \mathrm{mol} \mathrm{m} \mathrm{m}^{-2} \mathrm{~s}^{-1}$ and $16-\mathrm{h} / 8-\mathrm{h}\left(23 / 21^{\circ} \mathrm{C}\right)$ day/night regimes. Finally, five-day-old seedlings were then treated with the indicated chemicals, which were detailed described in the Figure legends.

\subsection{Measurement of Root Hairs}

For rapeseed, root hairs were counted and root hair length was measured in the root hair zone of fifteen roots in the third millimeter segment behind the tips by using a microscope (YS100, Nikon, Tokyo, Japan) [61]. Photographs were then taken with a Nikon digital camera (P5000 COOLPIX, Nikon, Tokyo, Japan). For Arabidopsis, root hairs were detected as previous described with some modification [27], and fifteen roots were taken for observations carried out on a $5 \mathrm{~mm}$ distance from root tip. Additional tests were carried out using rice, tomato, Chinese cabbage, wheat, radish, and alfalfa, and the calculations of their root hair density and length measurements were done as described previously [61].

\subsection{Detection of MWCNTs Distribution}

The distribution of MWCNTs was analyzed by transmission electron microscope as previously described [62]. Six samples from six different rapeseed root tissues (2-3 $\mathrm{mm}$ from the tip) per treatment were investigated. For each sample, 6 ultrathin sections were examined by transmission electron microscope (JEM-1400, JEOL, Tokyo, Japan).

\subsection{Measurement of Ethylene Production, ACC Oxidase, and ACC Synthase Activities}

According to methods described previously [27,34], ethylene production, ACC oxidase, and ACC synthase activities in roots was analyzed with a gas chromatograph (GC-7AG; Shimadzu, Tokyo, Japan).

\subsection{Determination of NO Content, Nitrate Reductase (NR), and NO Synthase (NOS) Activities}

According to the previous method [13,27,34], NO in root tissues was visualized using the specific NO probe 4-amino-5-methylamino-2', $7^{\prime}$-difluorofluorescein diacetate (DAF-FM DA) and observed by using a Zeiss LSM 800 confocal microscope (excitation $488 \mathrm{~nm}$, emission 490-530 nm; Carl Zeiss, Oberkochen, Germany). The lower right corners of the photograph were the corresponding brightfield (BF) images. The relative fluorescence was provided as values compared to the control.

According to the previous method [13,41], the NR activity in root tissues was determined spectrophotometrically at $540 \mathrm{~nm}$. 
The NOS activity was analyzed using the extinction coefficient of NADPH $\left(6.22 \mathrm{mM}^{-1} \mathrm{~cm}^{-1}\right)$ [13]. Protein content was also assayed [63].

\subsection{Analysis of Gene Transcription}

RNA isolation and cDNA synthesis were carried out as previously described [13]. Real-time quantitative RT-PCR (qPCR) was conducted, and the gene-specific primers were shown as in Supplementary Tables S2 and S3. Two internal control genes (rapeseed, BnActin, and BnGAPDH; Arabidopsis, AtActin 2, and AtGAPDH) were used, and the gene expression levels were presented as values compared to the corresponding control samples. The quantification of the relative transcript levels was calculated using the $2^{-\Delta \Delta \mathrm{CT}}$ method [63].

\subsection{Experimental Design}

All experiments were carried out in a random complete block design. Three independent experiments with at least three replicates for each were carried out, and three replicates included 45 seedlings $(15 \times 3)$ each time. At least 30 roots per treatment were used to detected NO fluorescence. To analyze the activities of ACC oxidase, ACC synthase, NR, and NOS activities, and the ethylene content, a specified weight of samples per treatment were used.

\subsection{Statistical Analysis}

Values are means \pm standard error (SE). Data were analyzed by one-way analysis of variance (ANOVA), taking $p<0.05$ as significant according to Duncan's multiple range test.

\section{Conclusions}

Taken together, by using pharmacology, genetics, and molecular approaches, we discovered the part of the molecular mechanism underlying MWCNTs-induced root hair formation in rapeseed and Arabidopsis. The results revealed that ethylene and NR-dependent NO are required for MWCNTs-induced root hair morphogenesis via regulating genes related to root hair development, and ethylene may act downstream of NO in this process.

Supplementary Materials: Supplementary materials can be found at http:/www.mdpi.com/1422-0067/21/23/ 9109/s1.

Author Contributions: Conceptualization, G.Z., Y.Z., and W.S.; methodology, G.Z., Y.Z., and W.L.; software, G.Z.; validation, Y.Z., W.L., and D.A.; formal analysis, R.G. and W.S.; investigation, G.Z. and W.S.; resources, W.S.; data curation, G.Z., Y.Z., and W.L.; writing_original draft preparation, G.Z., D.A., R.G., and W.S.; writing-review and editing, R.G. and W.S.; visualization, G.Z., Y.Z., and W.L.; supervision, W.S.; project administration, R.G. and W.S.; funding acquisition, G.Z. and W.S. All authors have read and agreed to the published version of the manuscript.

Funding: This research was funded by the National Key Research and Development Plan (2016YFD0101306, 2016YFD0101300) and the Postgraduate Research and Practice Innovation Program of Jiangsu Province (KYCX20_0566).

Acknowledgments: The author would like to thank Chongwei Jin of Zhejiang University for providing ein 2-5 and ein3-1 mutants.

Conflicts of Interest: The authors declare that they have no competing interests.

\section{Abbreviations}

$\begin{array}{ll}\text { CNTs } & \text { carbon nanotubes } \\ \text { MWCNTs } & \text { multi-walled carbon nanotube } \\ \text { NR } & \text { nitrate reductase } \\ \text { NO } & \text { nitric oxide } \\ \text { ACC } & \text { 1-aminocyclopropane-1-carboxylic acid } \\ \text { AVG } & \text { aminoethoxyvinylglycine } \\ \text { NOS } & \text { nitric oxide synthase }\end{array}$




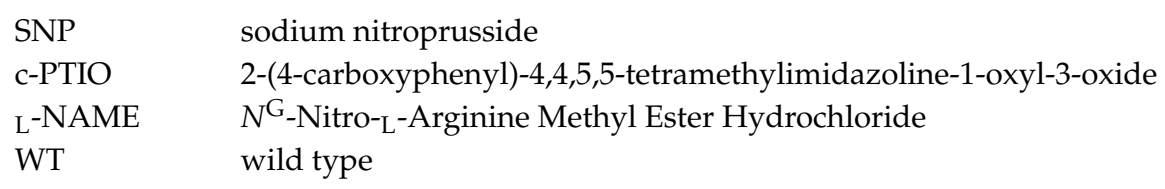

\section{References}

1. Iijima, S. Helical microtubules of graphitic carbon. Nat. Cell Biol. 1991, 354, 56-58. [CrossRef]

2. Iijima, S.; Ichihashi, T. Single-shell carbon nanotubes of 1-nm diameter. Nat. Cell Biol. 1993, 363, 603-605. [CrossRef]

3. Baughman, R.H.; Zakhidov, A.A.; De Heer, W.A. Carbon Nanotubes-The Route Toward Applications. Science 2002, 297, 787-792. [CrossRef] [PubMed]

4. Liné, C.; LaRue, C.; Flahaut, E. Carbon nanotubes: Impacts and behaviour in the terrestrial ecosystem-A review. Carbon 2017, 123, 767-785. [CrossRef]

5. Yin, Z.; Cui, C.; Chen, H.; Duoni; Yu, X.; Qian, W. The Application of Carbon Nanotube/Graphene-Based Nanomaterials in Wastewater Treatment. Small 2019, 16, e1902301. [CrossRef] [PubMed]

6. Tabuchi, M.; Baba, Y. Design for DNA Separation Medium Using Bacterial Cellulose Fibrils. Anal. Chem. 2005, 77, 7090-7093. [CrossRef]

7. Ma, C.; White, J.C.; Zhao, J.; Zhao, Q.; Xing, B. Uptake of Engineered Nanoparticles by Food Crops: Characterization, Mechanisms, and Implications. Annu. Rev. Food Sci. Technol. 2018, 9, 129-153. [CrossRef]

8. Peng, Z.; Liu, X.; Zhang, W.; Zeng, Z.; Liu, Z.; Zhang, C.; Liu, Y.; Shao, B.; Liang, Q.; Tang, W.; et al. Advances in the application, toxicity and degradation of carbon nanomaterials in environment: A review. Environ. Int. 2020, 134, 105298. [CrossRef]

9. Lahiani, M.H.; Dervishi, E.; Chen, J.; Nima, Z.; Gaume, A.; Biris, A.S.; Khodakovskaya, M.V. Impact of Carbon Nanotube Exposure to Seeds of Valuable Crops. ACS Appl. Mater. Interfaces 2013, 5, 7965-7973. [CrossRef]

10. Lahiani, M.H.; Chen, J.; Irin, F.; Puretzky, A.A.; Green, M.J.; Khodakovskaya, M.V. Interaction of carbon nanohorns with plants: Uptake and biological effects. Carbon 2015, 81, 607-619. [CrossRef]

11. Hatami, M.; Hadian, J.; Ghorbanpour, M. Mechanisms underlying toxicity and stimulatory role of single-walled carbon nanotubes in Hyoscyamus niger during drought stress simulated by polyethylene glycol. J. Hazard. Mater. 2017, 324, 306-320. [CrossRef] [PubMed]

12. Kumar, A.; Singh, A.; Panigrahy, M.; Sahoo, P.K.; Panigrahi, K.C.S. Carbon nanoparticles influence photomorphogenesis and flowering time in Arabidopsis thaliana. Plant Cell Rep. 2018, 37, 901-912. [CrossRef] [PubMed]

13. Shen, W.; Zhao, Y.; Lou, W.; Su, J.; Wei, S.; Yang, X.; Wang, R.; Guan, R.; Pu, H.; Shen, W. Nitrate reductase-dependent nitric oxide is crucial for multi-walled carbon nanotube-induced plant tolerance against salinity. Nanoscale 2019, 11, 10511-10523. [CrossRef]

14. Zaytseva, O.; Wang, Z.; Neumann, G. Phytotoxicity of carbon nanotubes in soybean as determined by interactions with micronutrients. J. Nanopart. Res. 2017, 19. [CrossRef]

15. Das, K.K.; You, Y.; Torres, M.; Barrios-Masias, F.H.; Wang, X.; Tao, S.; Xing, B.; Yang, Y. Development and application of a digestion-Raman analysis approach for studying multiwall carbon nanotube uptake in lettuce. Environ. Sci. Nano 2018, 5, 659-668. [CrossRef]

16. Fan, X.; Xu, J.; Lavoie, M.; Peijnenburg, W.; Zhu, Y.; Lu, T.; Ota, T.; Zhu, T.; Qian, H. Multiwall carbon nanotubes modulate paraquat toxicity in Arabidopsis thaliana. Environ. Pollut. 2018, 233, 633-641. [CrossRef]

17. Khodakovskaya, M.V.; Kim, B.-S.; Kim, J.N.; Alimohammadi, M.; Dervishi, E.; Mustafa, T.; Cernigla, C.E. Carbon Nanotubes as Plant Growth Regulators: Effects on Tomato Growth, Reproductive System, and Soil Microbial Community. Small 2013, 9, 115-123. [CrossRef]

18. Kumar, V.; Sachdev, D.; Pasricha, R.; Maheshwari, P.H.; Taneja, N.K. Zinc-Supported Multiwalled Carbon Nanotube Nanocomposite: A Synergism to Micronutrient Release and a Smart Distributor to Promote the Growth of Onion Seeds in Arid Conditions. ACS Appl. Mater. Interfaces 2018, 10, 36733-36745. [CrossRef]

19. Wang, C.; Liu, H.; Chen, J.; Tian, Y.; Shi, J.; Li, D.; Guo, C.; Ma, Q. Carboxylated multi-walled carbon nanotubes aggravated biochemical and subcellular damages in leaves of broad bean (Vicia faba L.) seedlings under combined stress of lead and cadmium. J. Hazard. Mater. 2014, 274, 404-412. [CrossRef] 
20. Gong, X.; Huang, D.; Liu, Y.; Zeng, G.; Wang, R.; Xu, P.; Zhang, C.; Cheng, M.; Xue, W.; Chen, S. Roles of multiwall carbon nanotubes in phytoremediation: Cadmium uptake and oxidative burst in Boehmeria nivea (L.) Gaudich. Environ. Sci. Nano 2019, 6, 851-862. [CrossRef]

21. Joshi, A.; Kaur, S.; Dharamvir, K.; Nayyar, H.; Verma, G. Multi-walled carbon nanotubes applied through seed-priming influence early germination, root hair, growth and yield of bread wheat (Triticum aestivum L.). J. Sci. Food Agric. 2018, 98, 3148-3160. [CrossRef] [PubMed]

22. García-Sánchez, S.; Bernales, I.; Cristobal, S. Early response to nanoparticles in the Arabidopsis transcriptome compromises plant defence and root-hair development through salicylic acid signalling. BMC Genom. 2015, 16, 1-17. [CrossRef] [PubMed]

23. Ketelaar, T. The actin cytoskeleton in root hairs: All is fine at the tip. Curr. Opin. Plant Biol. 2013, 16, 749-756. [CrossRef] [PubMed]

24. Potters, G.; Pasternak, T.P.; Guisez, Y.; Palme, K.; Jansen, M.A. Stress-induced morphogenic responses: Growing out of trouble? Trends Plant Sci. 2007, 12, 98-105. [CrossRef] [PubMed]

25. Tanimoto, M.; Roberts, K.J.; Dolan, L. Ethylene is a positive regulator of root hair development in Arabidopsis thaliana. Plant J. 1995, 8, 943-948. [CrossRef]

26. Dolan, L. The role of ethylene in root hair growth in Arabidopsis. J. Plant Nutr. Soil Sci. 2001, 164, 141-145. [CrossRef]

27. Liu, M.; Liu, X.X.; He, X.L.; Liu, L.J.; Wu, H.; Tang, C.X.; Zhang, Y.S.; Jin, C.W. Ethylene and nitric oxide interact to regulate the magnesium deficiency-induced root hair development in Arabidopsis. New Phytol. 2017, 213, 1242-1256. [CrossRef]

28. Feng, Y.; Xu, P.; Li, B.; Li, P.; Wen, X.; An, F.; Gong, Y.; Xin, Y.; Zhu, Z.; Wang, Y.; et al. Ethylene promotes root hair growth through coordinated EIN3/EIL1 and RHD6/RSL1 activity in Arabidopsis. Proc. Natl. Acad. Sci. USA 2017, 114, 13834-13839. [CrossRef]

29. Yang, S.F.; Hoffman, N.E. Ethylene Biosynthesis and its Regulation in Higher Plants. Annu. Rev. Plant. Physiol. 1984, 35, 155-189. [CrossRef]

30. Prasad, M.E.; Schofield, A.; Lyzenga, W.; Liu, H.; Stone, S.L. Arabidopsis RING E3 Ligase XBAT32 Regulates Lateral Root Production through Its Role in Ethylene Biosynthesis. Plant. Physiol. 2010, 153, 1587-1596. [CrossRef]

31. Lombardo, M.C.; Graziano, M.; Polacco, J.C.; LaMattina, L. Nitric Oxide Functions as a Positive Regulator of Root Hair Development. Plant. Signal. Behav. 2006, 1, 28-33. [CrossRef] [PubMed]

32. Lombardo, M.C.; LaMattina, L. Nitric oxide is essential for vesicle formation and trafficking in Arabidopsis root hair growth. J. Exp. Bot. 2012, 63, 4875-4885. [CrossRef] [PubMed]

33. Moro, C.F.; Gaspar, M.; Da Silva, F.R.; Pattathil, S.; Hahn, M.G.; Salgado, I.; Braga, M.R. S-nitrosoglutathione promotes cell wall remodelling, alters the transcriptional profile and induces root hair formation in the hairless root hair defective 6 (rhd6) mutant of Arabidopsis thaliana. New Phytol. 2016, 213, 1771-1786. [CrossRef] [PubMed]

34. Liu, M.; Zhang, H.; Fang, X.; Zhang, Y.S.; Jin, C. Auxin Acts Downstream of Ethylene and Nitric Oxide to Regulate Magnesium Deficiency-Induced Root Hair Development in Arabidopsis thaliana. Plant. Cell Physiol. 2018, 59, 1452-1465. [CrossRef]

35. Zhu, X.F.; Zhu, C.Q.; Wang, C.; Dong, X.Y.; Shen, R.F. Nitric oxide acts upstream of ethylene in cell wall phosphorus reutilization in phosphorus-deficient rice. J. Exp. Bot. 2017, 68, 753-760. [CrossRef]

36. Xu, X.-T.; Jin, X.; Liao, W.-B.; Dawuda, M.M.; Li, X.-P.; Wang, M.; Niu, L.-J.; Ren, P.-J.; Zhu, Y. Nitric oxide is involved in ethylene-induced adventitious root development in cucumber (Cucumis sativus L.) explants. Sci. Hortic. 2017, 215, 65-71. [CrossRef]

37. Naeem, M.S.; Warusawitharana, H.; Liu, H.; Liu, D.; Ahmad, R.; Waraich, E.A.; Xu, L.; Zhou, W. 5-Aminolevulinic acid alleviates the salinity-induced changes in Brassica napus as revealed by the ultrastructural study of chloroplast. Plant. Physiol. Biochem. 2012, 57, 84-92. [CrossRef]

38. Gale, M.D. Plant Comparative Genetics after 10 Years. Science 1998, 282, 656-659. [CrossRef]

39. Ledon, T.; Valle, E.; Valmaseda, T.; Cedré, B.; Campos, J.; Rodríguez, B.L.; Marrero, K.; García, H.; García, L.; Fando, R.; et al. Construction and characterisation of O139 cholera vaccine candidates. Vaccine 2003, 21, 1282-1291. [CrossRef]

40. Fancy, N.N.; Bahlmann, A.; Loake, G.J. Nitric oxide function in plant abiotic stress. Plant Cell Environ. 2016, 40, 462-472. [CrossRef] 
41. Cao, Z.; Zhou, H.; Kong, L.; Li, L.; Wang, R.; Shen, W. A Novel Mechanism Underlying Multi-walled Carbon Nanotube-Triggered Tomato Lateral Root Formation: The Involvement of Nitric Oxide. Nanoscale Res. Lett. 2020, 15, 1-10. [CrossRef] [PubMed]

42. Xie, Y.; Mao, Y.; Lai, D.; Zhang, W.; Zheng, T.; Shen, W. Roles of NIA/NR/NOA1-dependent nitric oxide production and HY1 expression in the modulation of Arabidopsis salt tolerance. J. Exp. Bot. 2013, 64, 3045-3060. [CrossRef] [PubMed]

43. Tossi, V.; LaMattina, L.; Cassia, R. An increase in the concentration of abscisic acid is critical for nitric oxide-mediated plant adaptive responses to UV-B irradiation. New Phytol. 2009, 181, 871-879. [CrossRef]

44. Chen, W.W.; Yang, J.L.; Qin, C.; Jin, C.W.; Mo, J.H.; Ye, T.; Zheng, S.J. Nitric Oxide Acts Downstream of Auxin to Trigger Root Ferric-Chelate Reductase Activity in Response to Iron Deficiency in Arabidopsis. Plant. Physiol. 2010, 154, 810-819. [CrossRef]

45. Lozano-Juste, J.; León, J. Enhanced Abscisic Acid-Mediated Responses in nia1nia2noa1-2 Triple Mutant Impaired in NIA/NR- and AtNOA1-Dependent Nitric Oxide Biosynthesis in Arabidopsis. Plant. Physiol. 2010, 152, 891-903. [CrossRef] [PubMed]

46. Bright, J.; Desikan, R.; Hancock, J.; Weir, I.S.; Neill, S.J. ABA-induced NO generation and stomatal closure in Arabidopsis are dependent on $\mathrm{H}_{2} \mathrm{O}_{2}$ synthesis. Plant. J. 2005, 45, 113-122. [CrossRef] [PubMed]

47. Wang, H.-H.; Huang, J.-J.; Bi, Y.-R. Nitrate reductase-dependent nitric oxide production is involved in aluminum tolerance in red kidney bean roots. Plant. Sci. 2010, 179, 281-288. [CrossRef]

48. Hu, Y.; You, J.; Liang, X. Nitrate reductase-mediated nitric oxide production is involved in copper tolerance in shoots of hulless barley. Plant. Cell Rep. 2014, 34, 367-379. [CrossRef] [PubMed]

49. Schiefelbein, J. Cell-fate specification in the epidermis: A common patterning mechanism in the root and shoot. Curr. Opin. Plant. Biol. 2003, 6, 74-78. [CrossRef]

50. Schiefelbein, J. Constructing a Plant Cell. The Genetic Control of Root Hair Development. Plant. Physiol. 2000, 124, 1525-1531. [CrossRef]

51. Molendijk, A.J.; Bischoff, F.; Rajendrakumar, C.S.; Friml, J.; Braun, M.; Gilroy, S.; Palme, K. Arabidopsis thaliana Rop GTPases are localized to tips of root hairs and control polar growth. EMBO J. 2001, 20, 2779-2788. [CrossRef] [PubMed]

52. Jones, M.A.; Shen, J.-J.; Fu, Y.; Li, H.; Yang, Z.; Grierson, C. The Arabidopsis Rop2 GTPase Is a Positive Regulator of Both Root Hair Initiation and Tip Growth. Plant Cell 2002, 14, 763-776. [CrossRef] [PubMed]

53. Růžička, K.; Ljung, K.; Vanneste, S.; Podhorská, R.; Beeckman, T.; Friml, J.; Benková, E. Ethylene Regulates Root Growth through Effects on Auxin Biosynthesis and Transport-Dependent Auxin Distribution. Plant Cell 2007, 19, 2197-2212. [CrossRef]

54. Jones, A.R.; Kramer, E.M.; Knox, K.; Swarup, R.; Bennett, M.J.; Lazarus, C.M.; Leyser, O.; Grierson, C.S. Auxin transport through non-hair cells sustains root-hair development. Nat. Cell Biol. 2009, 11, 78-84. [CrossRef]

55. Liu, W.-Z.; Kong, D.-D.; Gu, X.-X.; Gao, H.-B.; Wang, J.-Z.; Xia, M.; Gao, Q.; Tian, L.-L.; Xu, Z.-H.; Bao, F.; et al. Cytokinins can act as suppressors of nitric oxide inArabidopsis. Proc. Natl. Acad. Sci. USA 2013, 110, 1548-1553. [CrossRef]

56. Binder, B.; Mortimore, L.A.; Stepanova, A.N.; Ecker, J.R.; Bleecker, A.B. Short-Term Growth Responses to Ethylene in Arabidopsis Seedlings Are EIN3/EIL1 Independent. Plant. Physiol. 2004, 136, 2921-2927. [CrossRef]

57. Qiao, H.; Chang, K.N.; Yazaki, J.; Ecker, J.R. Interplay between ethylene, ETP1/ETP2 F-box proteins, and degradation of EIN2 triggers ethylene responses in Arabidopsis. Genes Dev. 2009, 23, 512-521. [CrossRef]

58. Qiao, H.; Shen, Z.; Huang, S.-S.C.; Schmitz, R.J.; Urich, M.A.; Briggs, S.P.; Ecker, J.R. Processing and Subcellular Trafficking of ER-Tethered EIN2 Control Response to Ethylene Gas. Sci. 2012, 338, 390-393. [CrossRef]

59. An, F.; Zhao, Q.; Ji, Y.; Li, W.; Jiang, Z.; Yu, X.; Zhang, C.; Han, Y.; He, W.; Liu, Y.; et al. Ethylene-Induced Stabilization of ETHYLENE INSENSITIVE3 and EIN3-LIKE1 Is Mediated by Proteasomal Degradation of EIN3 Binding F-Box 1 and 2 That Requires EIN2 in Arabidopsis. Plant. Cell 2010, 22, 2384-2401. [CrossRef]

60. Ju, C.; Yoon, G.M.; Shemansky, J.M.; Lin, D.Y.; Ying, Z.I.; Chang, J.; Garrett, W.M.; Kessenbrock, M.; Groth, G.; Tucker, M.L.; et al. CTR1 phosphorylates the central regulator EIN2 to control ethylene hormone signaling from the ER membrane to the nucleus in Arabidopsis. Proc. Natl. Acad. Sci. USA 2012, 109, 19486-19491. [CrossRef]

61. Guo, K.; Kong, W.W.; Yang, Z.M. Carbon monoxide promotes root hair development in tomato. Plant Cell Environ. 2009, 32, 1033-1045. [CrossRef] [PubMed] 
62. Martínez-Ballesta, M.D.C.; Zapata, L.; Chalbi, N.; Carvajal, M. Multiwalled carbon nanotubes enter broccoli cells enhancing growth and water uptake of plants exposed to salinity. J. Nanobiotechnol. 2016, 14, 1-14. [CrossRef] [PubMed]

63. Chen, Z.; Xie, Y.; Gu, Q.; Zhao, G.; Zhang, Y.; Cui, W.; Xu, S.; Wang, R.; Shen, W. The AtrbohF-dependent regulation of ROS signaling is required for melatonin-induced salinity tolerance in Arabidopsis. Free Radic. Biol. Med. 2017, 108, 456-477. [CrossRef] [PubMed]

Publisher's Note: MDPI stays neutral with regard to jurisdictional claims in published maps and institutional affiliations.

(C) 2020 by the authors. Licensee MDPI, Basel, Switzerland. This article is an open access article distributed under the terms and conditions of the Creative Commons Attribution (CC BY) license (http://creativecommons.org/licenses/by/4.0/). 